\title{
Development and validation of HPTLC method for estimation of dofetilide in pharmaceutical dosage form and determination of its degradation profile by MS-MS method
}

\author{
Ritesh Bhole ${ }^{1}$ (D) Khandu Chadar ${ }^{1}$ (D), Yogesh Zambare ${ }^{1}$ (D), Chandrakant G. Bonde ${ }^{2}$ (i) \\ 'Dr. D. Y. Patil Institute of Pharmaceutical Sciences and Research, Department of Pharmaceutical Quality Assurance, \\ Pune, India \\ ${ }^{2}$ SVKM, School of Pharmacy, Shirpur, Dist: Dhule
}

ORCID IDs of the authors: R.B. 0000-0003-4088-7470; K.C. 0000-0002-0614-6305; Y.Z. 0000-0001-5115-0971;

C.G.B. $0000-0001-5712-1119$

Cite this article as: Bhole, R., Chadar, K., Zambare, Y., \& Bonde, C.G. (2020). Development and validation of HPTLC method for estimation of dofetilide in pharmaceutical dosage form and determination of its degradation profile by MS-MS method. İstanbul Journal of Pharmacy, 50 (2), 71-78.

\begin{abstract}
Background: Dofetilide is the class III antiarrhythmic drug used as a potassium channel blocker approved by US FDA in 1999 for the maintenance of sinus rhythm in individuals prone to atrial flutter and atrial fabrication. Currently there is no HPTLC-MS method reported for systematic characterization of degradation products dofetilide.

Methods: As per the ICH guidelines, the HPTLC method for the determination of dofetilide both in bulk and pharmaceutical formulation has been developed and validated. The degradation products were identified and characterized by using MS/MS. The Rf value was found to be $0.52 \pm 0.3$. The degradation study was performed as per ICH guidelines (Q2R1). Isolation of the degradation product by HPTLC method and categorized by MS/MS method.

Results: The linearity of the method was found suitable over the range $100-600 \mathrm{ng} / \mathrm{band}$ with $\mathrm{r}^{2}$ of 0.998 . Dofetilide was subjected to stability studies, the drug was found to degrade under various stress conditions. The recovery was found in the range of $98-101 \%$. HPTLC-MS/MS method showed a possible degradation mechanism of 7 degrading products. The degradation of the drug under various stress conditions indicates the storage conditions for the drug and drug product during its shelf life.

Conclusion: The HPTLC method developed for its linearity, range, precision studies, LOD and LOQ can be used for the routine quality control of the drug dofetilide in bulk drugs. The degradation pathway of a drug can help in the future to identify the impurities and for the impurity profiling of dofetilide.
\end{abstract}

Keywords: Stability indicating, HPTLC, HPTLC-MS/MS degradation studies, dofetilide

\section{INTRODUCTION}

Dofetilide (Figure 1) is the class III antiarrhythmic drug used as a potassium channel blocker approved by US FDA in 1999 for the maintenance of sinus rhythm in individuals prone to atrial flutter and atrial fabrication with a very potent dosage form in
0.25, 0.250 and $0.500 \mathrm{mg}$ capsules of Dofetilide. (Wells, Khairy, Harris, Anderson, \& Balaji, 2009; Krafte, \& Volberg, 1994; Woolf, Miler, \& Gosting, 1962). This dosage form is manufactured by Pfizer. (Wells et al., 2009; Aktas, Shah, \& Akiyama, 2007; AlDashti, \& Sami, 2001). The method refined by HPTLC was vali- 
dated for linearity range, interday and intraday precision, Limit of Quantitation (LOQ) and Limit of Detection (LOD) according to ICH Q2R1 guidelines. (2005: ICH Guidelines)

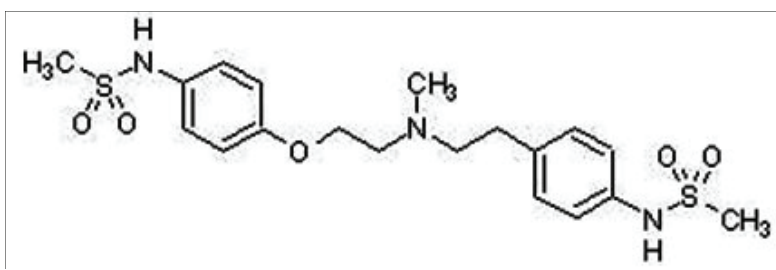

Figure 1. Structure of Dofetilide.

Dofetilide is a drug that can target potassium channels present in the cardiac region with good potency. (Bhole, Naksarkhre, \& Bonde, 2019; Udin, Sung, Hunge, \& Hu, 2019; Qile, Henriett, \& David, 2019; Chi, Liu, \& Wang, 2017; Kaddar, Pilote, Wong, Caillier, \& Patoine, 2013; Mounsey, \& DiMarco, 2007; Clusin, 2003), this can be an alternative therapy or considered as an aid for the currently available methods (catheter-based ablation and alternative pharmacological approach for the treatment of atrial arrhythmias.) According to ICH guidelines - Q1A (R2) the degradation of the drug under various stress conditions may help for the determination of stability of the drug. The forced degradation studies of drug substance or product should be evaluated for the development of stability-indicating methods. As per the prescribed guidelines, 20\% degradation is within the acceptable range. As per the Literature review there are some methods reported for quantification of Dofetilide in pure form or in its pharmaceutical dosage form. (Udin et al., 2019; Chi et al., 2017; Bhole, Shinde, Chitlange, \& Wankhede, 2015). On the other hand, high performance thin-layer chromatography (HPTLC) is a promising sustainable alternative to HPLC in some analysis. As HPTLC, separations has several advantages, it takes a short time for analysis. Moreover, it requires few nanoliter injection volumes. Furthermore, minimal use of solvent and no prior extraction steps compared to HPLC. However, There are very few HPTLC determination methods are available for the drug dofetilide as per literature. Some of these methods also report the degradation behavior under some stress conditions. As the solvent used in these methods are not very cost effective. It was also noted that there is an emerging need to perform a systematic characterization of degradation products by using MS-MS technique (Bhole, Biradar, \& Bonde, 2018). So the current study was performed to develop selective and highly sensitive, specific, cost-effective and precise HPTLC method for determination of Dofetilide in presence of their degradation products and also in its dosage form. Moreover, the isolated stressed sample of Dofetilide was characterized by MS/MS method and also its possible degradation pathway was proposed.

\section{MATERIALS AND METHODS}

\section{Chemicals and Reagents}

Toluene, methanol, triethylamine, dofetilide

\section{Instrumentations}

Precoated aluminium plates with silica gel 60 F254 plates (Merck, Germany; supplied by Merck India, Mumbai, India). Ca- mag Linomat V (Muttenz, Switzerland). The pressure requirement for the sample application is $4 \mu \mathrm{L}$. Dimension $360 \mathrm{~mm} x$ 510 mm x 410 mm (Width x Length x Height)]. Camag $100 \mu \mathrm{L}$ syringe (Hamilton, Bonaduz, Switzerland). Camag twin trough glass chamber $(10 \times 10 \mathrm{~cm}$ and $10 \times 20 \mathrm{~cm})$. It has the dualwavelength function (254 and $366 \mathrm{~nm}$ ) [Dimension: $477 \mathrm{~mm} \times$ $343 \mathrm{~mm} \times 285$ mm (Length $\times$ Width $\times$ Height)].

\section{Chromatographic Conditions}

$4 \mu \mathrm{L}$ of sample and standard solutions are applied on the TLC plate by using Camag Linomat $V$ automatic sample applicator in the form of band (band with: $6 \mathrm{~mm}$, and the distance is 5.6 $\mathrm{mm}$ between two bands) using micro-syringe. In twin trough glass chambers, the plates were saturated (10 minutes) with the mobile phase of composition toluene: methanol: triethylamine (7:2.5:0.5, v/v/v). Ascending development was performed up to a distance of $8 \mathrm{~cm}$ by placing the plates in the mobile phase. Later the development, the plates were dried in air and a densitometric scanning (slit dimensions: $5 \times 0.45$ ) was performed at 231 nm using Camag TLC scanner III operated in reflectanceabsorbance mode (Bhole et al., 2018; Bonthagarala, 2003).

\section{Analysis Formulation \\ Preparation of Standard Stock Solution}

Accurately weighed $12.5 \mathrm{mg}$ Dofetilide, transferred to 100.0 $\mathrm{mL}$ volumetric flask, and dissolved in AR grade 25 methanol by ultra-sonicating for 10 min and volume was made up to the mark using the methanol to give a stock solution of concentration $0.125 \mathrm{mg} / \mathrm{mL}$ or $125 \mu \mathrm{g} / \mathrm{mL}$. Further dilution $8 \mathrm{ml}$ stock solution to $10 \mathrm{~mL}$ (concentration $100 \mu \mathrm{g} / \mathrm{mL}$ ) to above solution of dofetilide was applied on the TLC plates in the range 0.1 to 0.6 $\mu \mathrm{L}$ i.e. $100-600 \mathrm{ng} / \mathrm{band}$ of dofetilide with the help of Hamilton syringe using LINOMAT-V automatic sample applicator. The plate was then developed in an optimized mobile phase. Different mobile phase combinations were tested and finally this ratio selected for the method development on HPTLC. The mobile phase ratio is methanol: toluene: triethylamine (7:2.5:0.5) was selected as it gives good resolution and peak symmetry for dofetilide. The Rf value for dofetilide was found to be 0.52 respectively (Fegade, Bhole, Patil, \& Chaudhari, 2009; Rakibe, Tiwari, Mahajan, Rane, \& Wakte, 2018).

\section{Preparation of Sample Solution}

(Each capsule contains 0.500 mg of Dofetilide) 25 capsules shells were opened and the powder was weighed equivalent to $12.5 \mathrm{mg}$ (13.75 mg with excipients) of the Dofetilide sample into a $100 \mathrm{ml}$ clean volumetric flask added about $40 \mathrm{ml}$ of diluents and sonicated up to 10 min to completely dissolve and diluted up to the mark with diluents. The final concentration of the stock solution was $125 \mu \mathrm{g} / \mathrm{ml}$. then further dilution. Further dilution $8 \mathrm{ml}$ to $10 \mathrm{ml}$ (concentration 100 mg/ml). (Jadhav, Nimbalkara, Mathad, \& Mali, 2013).

\section{Selection of Working Wavelength ( $\lambda$ max)}

The UV spectrum of $4 \mu \mathrm{g} / \mathrm{mL}$ of Dofetilide in methanol, the spectrum was recorded by scanning in the range $(200 \mathrm{~nm}$ to $400 \mathrm{~nm}$ ). From the UV spectrum wavelength selected as 231 $\mathrm{nm}$. The spectrum was shown in Figure 2 (Shivashankar, \& Gandhimathi, 2005). 


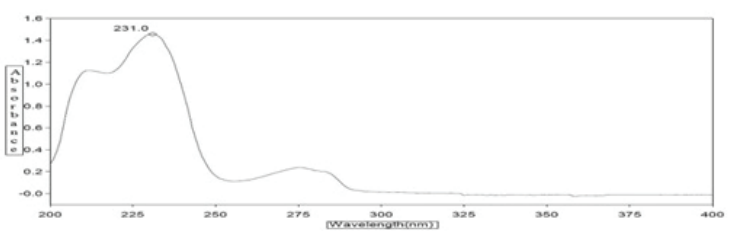

Figure 2. UV-VIS spectrum was found to be $231 \mathrm{~nm}$ for Dofetilide.

\section{Method Validation}

The method was validated in compliance with $\mathrm{ICH}$ guidelines.

\section{Linearity}

The linearity of the method was evaluated at the five equalspaced concentrations (Ceresole, Moyano, Pizzorno, \& Segall, 2007) by diluting the standard stock solution to give solution over the range of 100-600 ng/band of dofetilide. A calibration curve was constructed at six linear concentrations of dofetilide (0.1 to $0.6 \mu \mathrm{g} / \mathrm{mL}$ ). solutions were injected into the chromatographic system, after getting the results plotted a graph concentration versus an area to evaluate correlation coefficient.

Acceptance criteria: Correlation coefficient Not less than 0.99.

\section{Accuracy \& Recovery}

Accuracy solutions prepared into three levels (80\%, 100\%, and $120 \%)$. For each level the preparations were prepared individually. 80\%, 100\% \& 120\% Solutions were prepared with different drug weights with a constant weight of placebo in the manner of sample preparation.

Acceptance Criteria: \% Recovery should be 98.0 to 102.0 Acceptance Criteria: \% RSD for nine preparations recover values should be $\leq 2.0$

\section{Precision}

Method precision, validation parameter investigated using the six individual sample preparations as reported above. Six samples were injected individually into the chromatographic system and calculated the \% assay of individual samples. Repeatability and Intermediate precision (Intraday and Interday precision).

Acceptance Criteria: \% Assay should be 95.0 to 105 \& \%RSD for six preparations assay should be $\leq 2.0$.

\section{Robustness}

To evaluate the robustness of the proposed method, small but deliberate variations in the optimized method parameters were done. By introducing small changes in the mobile phase composition, mobile phase volume and duration of chamber saturation with the mobile phase, the effects on the Rf value of drugs were examined. The composition of the mobile phase was changed slightly ( $\pm 0.1 \mathrm{~mL}$ for the component). Robustness of the method was performed as per the standard guidelines.

Acceptance Criteria: System suitability should be within the acceptance criteria: System suitability should be within the acceptance criteria.

\section{Limit of LOD and LOQ}

The LOD and LOQ of the developed method were calculated by using the standard method

Acceptance Criteria: $\leq 2$

\section{Forced Degradation Studies}

The stability of the drug was studied at various stress conditions as indicated by the ICH guidelines Q1A (R2) for acid hydrolysis with $0.1 \mathrm{M} \mathrm{HCl}$, base hydrolysis with $0.1 \mathrm{M} \mathrm{NaOH}, 3 \%$ hydrogen peroxide for oxidation, thermal degradation at $40^{\circ} \mathrm{C}$, $60^{\circ} \mathrm{C}, 80^{\circ} \mathrm{C}$, and photolysis. Accurately weighed the quantity of capsule powder equivalent to about $12.5 \mathrm{mg}$ of Dofetilide was transferred separately to six different $10.0 \mathrm{ml}$ volumetric flask, (flask no. 1, 2, 3, 4, 5 and 6). To flask no.1, 2 and 3, followed by the addition of $3.0 \mathrm{~mL}$ of $0.1 \mathrm{M} \mathrm{HCl}, 3.0 \mathrm{~mL}$ of $0.1 \mathrm{M} \mathrm{NaOH}, 3 \mathrm{~mL}$ water for neutral hydrolysis and $3 \% \mathrm{H}_{2} \mathrm{O}_{2}$ respectively. The content of flask no. 1, 2, 3 and 4 were heated in a water bath at $80^{\circ} \mathrm{C}$ for 1 hrs 30 min, 30 min, 1 hr and 2 hrs 30 min respectively. The flask no. 5 containing powder kept in a hot air oven at $600^{\circ} \mathrm{C}$ for 10 min to study the effect of heat on the sample (heat degradation). Flask no. 6 containing powder was exposed to UVradiations for 72 hrs to study the effect of light on the sample (photodegradation). The Whatman filter paper no 42 is used for filtration. From the filtrate, the $1.0 \mathrm{~mL}$ solution was diluted to 10 $\mathrm{mL}$ with the mobile phase. The diluted solution was analyzed similarly as described under the analysis of marketed formulation. The typical dendrogram was shown in Figure 3.

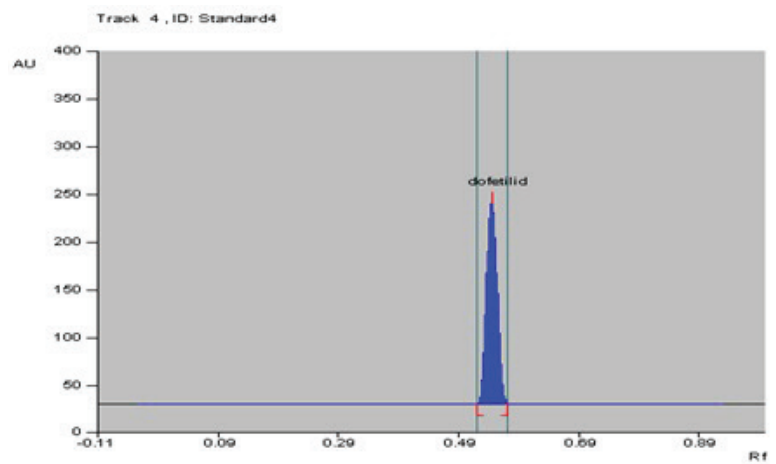

Figure 3. Typical densitiogram of Dofetilide retention factor: $0.52( \pm 0.03)$.

\section{RESULT AND DISCUSSION}

These studies were performed to develop a sensitive method, and an economically and less time-consuming HPTLC technique, which may be implemented for the determination of Dofetilide in pharmaceutical formulation. The HPTLC method was developed as per the stated method. Such as a large number of samples handle easier to scan the band and the detector response is higher. The chromatographic saturation is $10 \mathrm{~min}$ utes. Many trial and error methods were tried by using various solvents with altering polarity and in the diverse extent to obtain superior resolution and sharp peaks with acceptable Rf values (0.1-0.6 $\mu \mathrm{g} / \mathrm{band}$ ). Amongst the various mobile phase blend tested, mobile phase consisting of toluene: methanol: triethylamine (7:2.5:0.5 v/v/v) shows enhanced resolution and sharp 
peaks with Rf values of $0.5205 \pm 0.05$ of dofetilide. The linearity graph and linearity table are shown in Figure 4 and Table 1.

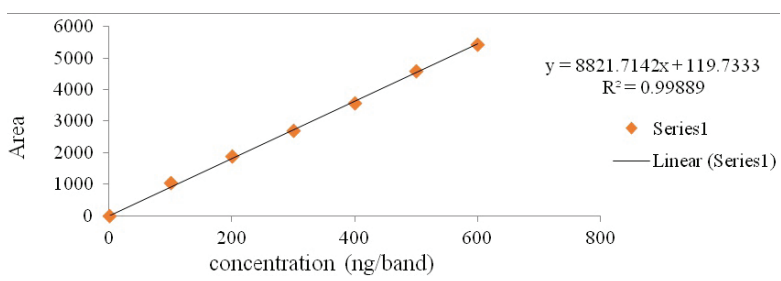

Figure 4. Linearity graph.

Table 1. Calibration parameter.

\begin{tabular}{|lc|}
\hline Parameters & Dofetilide \\
\hline Linearity Range & $100 \mathrm{ng} /$ band \\
Linearity Equation & $\mathrm{Y}=8221.742 \mathrm{x}+119.7333$ \\
Correlation Coefficient & 0.998 \\
\hline
\end{tabular}

\section{Accuracy (Recovery)}

To determine the accuracy of the said methods, accuracy studies were carried out as per ICH guidelines. The determination was performed in triplicate at each level was shown in Table 2.

\section{Table 2. Recovery study.}

\begin{tabular}{|lccc|}
\hline Level of recovery & \% Recovery* & S.D. & R.S.D. \\
\hline $\mathbf{8 0 \%}$ & 98.93 & 0.29 & 0.29 \\
$\mathbf{1 0 0 \%}$ & 99.37 & 0.45 & 0.46 \\
$\mathbf{1 2 0 \%}$ & 99.65 & 0.12 & 0.12 \\
\hline
\end{tabular}

*Mean of three determinations

\section{Precision}

The precision study was performed as per the standard method. The \% RSD for intraday and interday precision is less than 2 , indicating the precision of the method as shown in Table 3.

Table 3. Precision of developed method.

\begin{tabular}{|lccc|}
\hline Precision parameter & \% label claim & S.D. & \%R.S.D. \\
\hline Repeatability & 98.03 & 1.12 & 1.14 \\
Intraday & 99.70 & 0.10 & 0.10 \\
Interday & 99.20 & 0.20 & 0.20 \\
\hline *Mean of three determinations & & \\
\hline
\end{tabular}

\section{Robustness}

The mobile phase composition changed within a range of \pm 1 $\mathrm{ml}$. Moreover, the chamber saturation time was varied in the range of and $\pm 2.5 \mathrm{~min}$, respectively. The effect of these changes on both the Rf values and peak area was shown in Table 4.
Table 4. Result of robustness study

\begin{tabular}{|c|c|c|c|}
\hline \multicolumn{4}{|c|}{ Robustness study } \\
\hline Factor & Level & Area & $\mathbf{R f}$ \\
\hline \multicolumn{4}{|c|}{ Mobile Phase Composition ( $\pm 0.1 \mathrm{ml}$ ) } \\
\hline 6.9:2.6:0.5 & -0.1 & 3670 & 0.53 \\
\hline 7:2.5:0.5 & 0 & 3660 & 0.52 \\
\hline 7.1:2.4:0.5 & +0.1 & 3675 & 0.55 \\
\hline \%RSD & & 0.21 & \\
\hline \multicolumn{4}{|c|}{ Duration for Chamber saturation ( $\pm 5 \mathrm{~min}$ ) } \\
\hline $5 \mathrm{~min}$ & $-5 \min$ & 3670 & 0.49 \\
\hline $10 \mathrm{~min}$ & $0 \mathrm{~min}$ & 3675 & 0.52 \\
\hline $15 \mathrm{~min}$ & $+5 \min$ & 3690 & 0.57 \\
\hline \multicolumn{4}{|c|}{ Volume of mobile phase $( \pm 1 \mathrm{ml})$} \\
\hline $9.0 \mathrm{ml}$ & $-1 \mathrm{ml}$ & 3699 & 0.50 \\
\hline $10.0 \mathrm{ml}$ & $0 \mathrm{ml}$ & 3674 & 0.52 \\
\hline $11.0 \mathrm{ml}$ & $+1 \mathrm{ml}$ & 3620 & 0.52 \\
\hline
\end{tabular}

\section{LOD and LOQ}

Limit of detection and Limit of quantification were done separately and found to be $0.17 \mathrm{ng} / \mathrm{band}$ for dofetilide. LOQ was found to be $0.51 \mathrm{ng} / \mathrm{band}$ for Dofetilide.

\section{Analysis of Formulation}

Twenty-five capsules (Tikosyn) were weighed and crushed to obtain a fine powder. The average weight of the capsule was calculated. Accurately weighed the quantity of capsule powder equivalent to about 500 mcg of Dofetilide. The content of the drug was close to $100 \%$. The result was summarized in Table 5 and 6.

\section{Table 5. Marketed formulation}

\begin{tabular}{|ccccc|}
\hline \multicolumn{2}{c}{ Tikosyn } & \multicolumn{2}{c|}{ Label claim: 500 mcg } \\
\hline Sr. No. & $\begin{array}{c}\text { Wt. of capsule } \\
\text { powder (mcg) }\end{array}$ & $\begin{array}{c}\text { Peak } \\
\text { area* }\end{array}$ & $\begin{array}{c}\text { Amount } \\
\text { found (mcg) }\end{array}$ & $\begin{array}{c}\text { \% label } \\
\text { claim }\end{array}$ \\
\hline 1. & 550 & 3669 & 492 & 98.40 \\
2. & 550 & 3637 & 480 & 96.00 \\
3. & 550 & 3680 & 490 & 98.00 \\
4. & 550 & 3669 & 490 & 98.00 \\
5. & 550 & 3680 & 497 & 99.40 \\
6. & 550 & 3643 & 492 & 98.40 \\
\hline *Mean of three determinations \\
\hline \multicolumn{5}{|r}{} \\
\hline
\end{tabular}

Table 6. Statistical validation for analysis of marketed formulation

\begin{tabular}{|lcccc|}
\hline Drug & $\begin{array}{c}\text { Amount of drug } \\
\text { found }(\mathrm{mcg})\end{array}$ & $\begin{array}{c}\text { \% Label } \\
\text { claim* }\end{array}$ & $\begin{array}{c}\text { S.D. } \\
( \pm)\end{array}$ & R.S.D. \\
\hline Dofetilide & 490.16 & 98.03 & 1.12 & 1.14 \\
\hline * Mean of six determination & & & \\
\hline
\end{tabular}


Bhole et al. Development and validation of HPTLC method for estimation of dofetilide in pharmaceutical dosage form and determination of its degradation profile by MS-MS method

\section{Forced Degradation Studies}

Dofetilide was found to degrade in various stress conditions (acid, alkaline, and oxidation). Utmost degradation was observed in the said conditions, (alkaline, acid, neutral, heat, and photodegradation). Percentage assay of active substance along with Rf values of degradation products is summarized in Table 7 and Figures 5-10. (alkaline, acid, neutral, heat, and photodegradation stress conditions). Acid degradation shows two peaks.

\section{Table 7. Result of degradation studies}

\begin{tabular}{|c|c|c|c|c|}
\hline $\begin{array}{l}\text { Sr. } \\
\text { No. }\end{array}$ & $\begin{array}{l}\text { Stress } \\
\text { Condition }\end{array}$ & $\begin{array}{c}\text { Tempera- } \\
\text { ture and } \\
\text { Time }\end{array}$ & $\begin{array}{c}\% \text { assay } \\
\text { of active } \\
\text { substance }\end{array}$ & $\begin{array}{c}\text { Rf of } \\
\text { degraded } \\
\text { product }\end{array}$ \\
\hline 1 & $\begin{array}{c}\text { Acid } \\
(0.1 \mathrm{M} \mathrm{HCl})\end{array}$ & $\begin{array}{l}80^{\circ} \mathrm{C} \text { for } \\
1 \mathrm{hr} 30 \mathrm{~min}\end{array}$ & 89.96 & $0.03,0.60$ \\
\hline 2 & $\begin{array}{c}\text { Alkali } \\
(0.1 \mathrm{M} \mathrm{NaOH})\end{array}$ & $\begin{array}{l}80^{\circ} \mathrm{C} \text { for } \\
30 \mathrm{~min}\end{array}$ & 86.96 & $\begin{array}{c}0.07,0.20 \\
0.58\end{array}$ \\
\hline 3 & Neutral $\left(\mathrm{H}_{2} \mathrm{O}\right)$ & $\begin{array}{c}80^{\circ} \mathrm{C} \text { for } \\
1 \mathrm{hr}\end{array}$ & 91.89 & $\begin{array}{l}0.07,0.12 \\
0.16,0.23\end{array}$ \\
\hline 4 & $\begin{array}{c}\text { Oxide } \\
\left(3 \% \mathrm{H}_{2} \mathrm{O}_{2}\right)\end{array}$ & $\begin{array}{c}80^{\circ} \mathrm{C} \text { for } \\
2 \mathrm{hr} 30 \mathrm{~min}\end{array}$ & 91.64 & 0.08 \\
\hline 5 & Thermal & $\begin{array}{l}60^{\circ} \mathrm{C} \text { for } \\
10 \mathrm{~min}\end{array}$ & 91.25 & $\begin{array}{c}0.08,0.16 \\
0.23\end{array}$ \\
\hline 6 & $\begin{array}{c}\text { Photo } \\
\text { Degradation }\end{array}$ & $24 \mathrm{hr}$ & 90.71 & $0.60,0.64$ \\
\hline
\end{tabular}

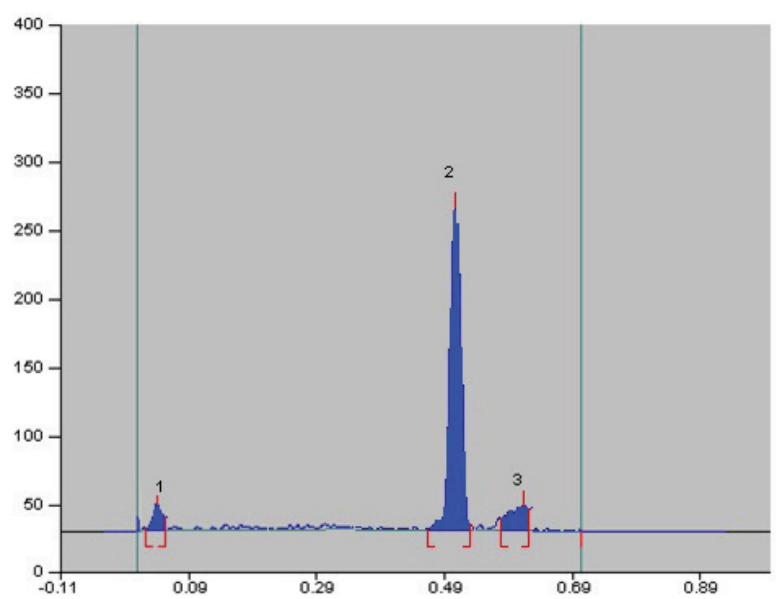

Figure 5. Densitogram of acid $(0.1 \mathrm{M} \mathrm{HCl})$ treated sample.

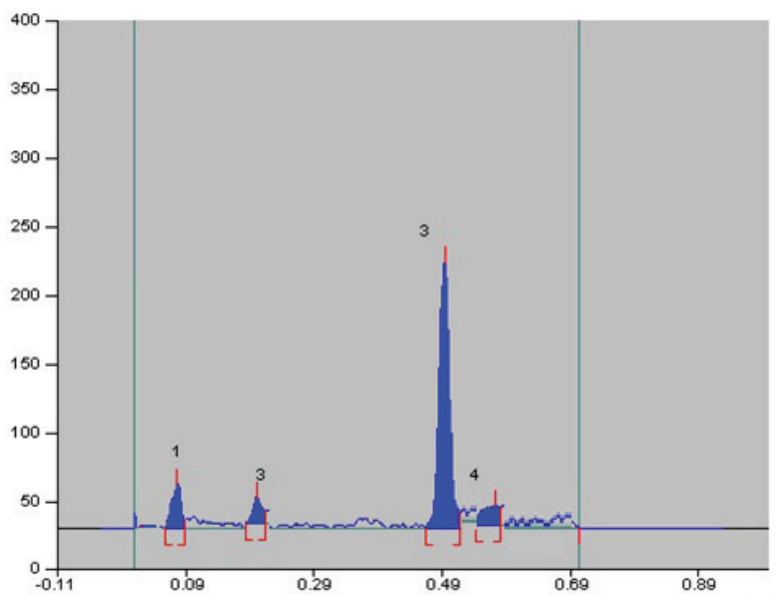

Figure 6. Densitogram of alkali $(0.1 \mathrm{M} \mathrm{NaOH})$ treated sample.

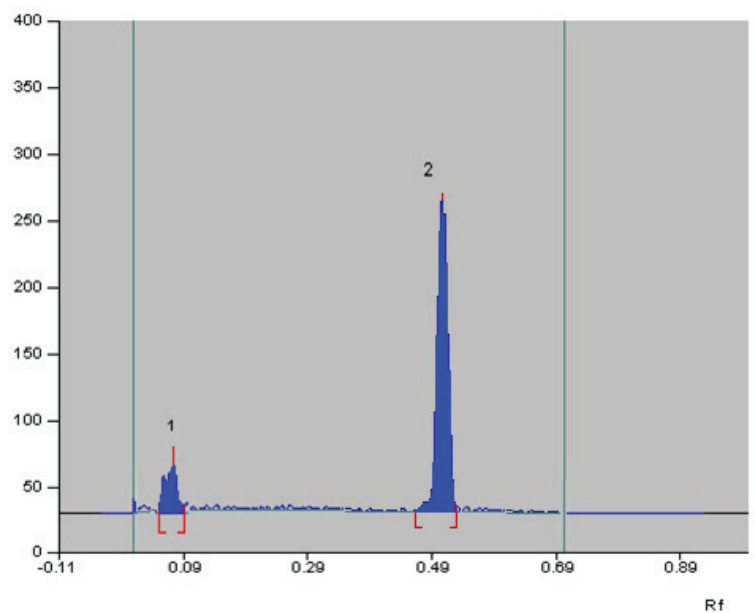

Figure 7. Densitogram of oxide $\left(3 \% \mathrm{H}_{2} \mathrm{O}_{2}\right)$ treated sample.

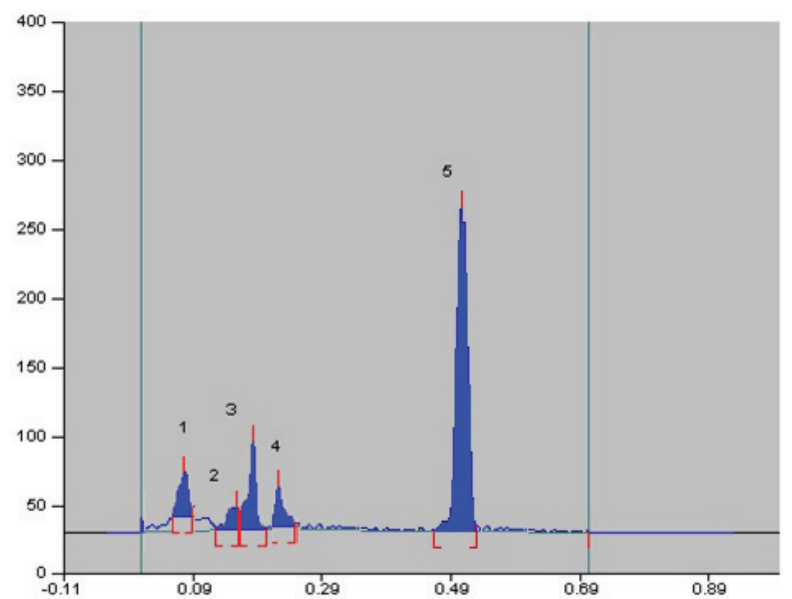

Figure 8. Densitogram of the sample exposed to neutral hydrolysis.

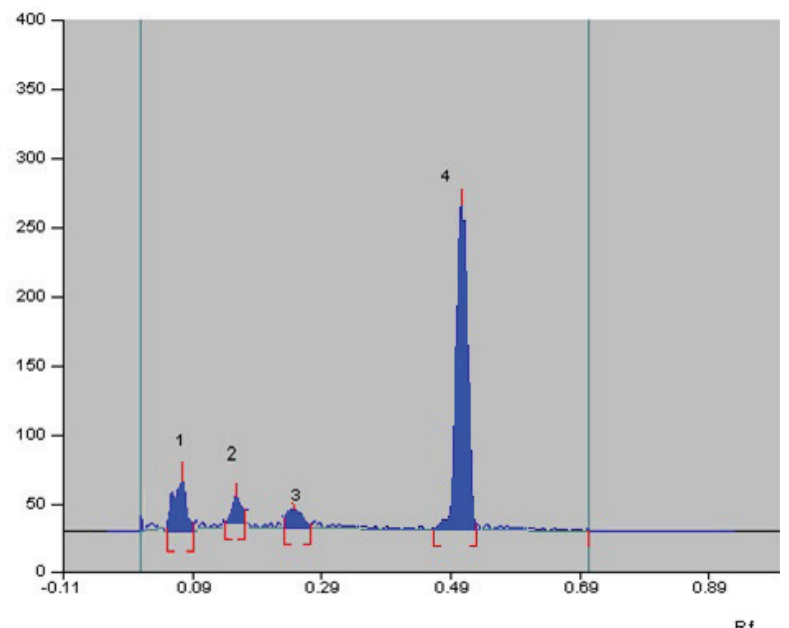

Figure 9. Densitogram of the sample exposed to heat.

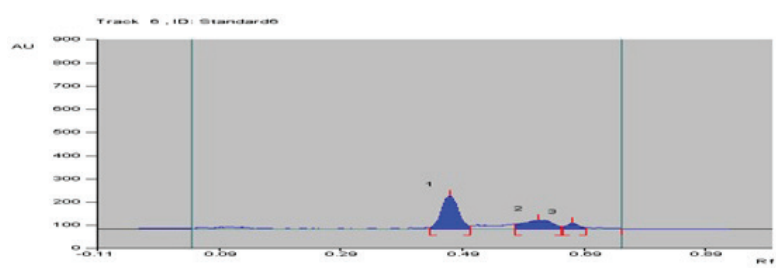

Figure 10. Densitogram of the sample exposed to photodegradation. 


\section{Separation, Characterization of Degradation Product by HPTLC and by MS/MS (Tandem Mass Spectroscopy) Method}

Isolation of degradation product by using HPTLC method

An accurately weighed quantity of $10.0 \mathrm{mg}$ of Dofetilide was transferred to $10.0 \mathrm{~mL}$ of volumetric flask than add $3.0 \mathrm{ml}$ of distilled water flask no.1 $3.0 \mathrm{~mL}$ of $0.1 \mathrm{M}$ acid in flask no 2, $0.1 \mathrm{M}$ $\mathrm{NaOH}$ in flask no 3, 3\% of $\mathrm{H}_{2} \mathrm{O}_{2}$ in flask no 4. The forced degradation study was carried out by exposing samples to the stress condition as $0.1 \mathrm{M} \mathrm{HCl}, 0.1 \mathrm{M} \mathrm{NaOH}$, neutral, oxide for degradation, contents of the flask were reflux in a water bath at $80^{\circ} \mathrm{C}$ for $1 \mathrm{hr} 30 \mathrm{~min}, 30 \mathrm{~min}, 1 \mathrm{hr}$ and $2 \mathrm{hr} 30$ min respectively. After the respective time intervals, all the flasks were removed and allowed to cool. Then the samples were applied on the TLC plate with the sample volume of about $10 \mu \mathrm{L} /$ band, 4 band of degraded sample and 1 band of std. were applied. Then the TLC plate was allowed to develop under optimized chromatographic conditions for Dofetilide. After development of the plate these plates were kept under the UV chamber on the basis of Rf value of the std. and degradation product they are marked and that portion of TLC plate was cut and allowed it to extract into methanol. Then the IR spectra and MS-MS spectra was recorded for interpretation of the probable structure of the degradation product. The diagrammatic procedure was given below degradation of sample in acid, alkali, oxide and neutral stressed condition.

The said degradation products were then subjected to MS/MS studies by using positive electrospray ionization (ESI) mode (mass range of 50-1500 daltons). The drug (concentration of $6 \mu \mathrm{g} / \mathrm{mL}$ ) was directly infused using a syringe pump into MS/MS in methanol: water (50:50 v/v) as a solvent system. This is for the optimization of mass parameters which inform about the molecular ion peak of the drug. These were further modified to get complete fragmentation of the drug. High purity nitrogen was used as the nebulizer as well as the auxiliary gas (Bhole, Naksarkhre, \& Bonde, 2019; Bhole et al., 2018). Fragmentation of various precursor ions formed in MS/MS studies was achieved at different collision energies The seven degrading products were observed in the four neutral stress conditions, two in acidic stress condition, two in alkaline stress condition and one in oxidative stress condition. (Molecular formula C19H27N3O5S2; Molecular weight: 441.56) i.e. DP-1, DP-2, DP-3, DP-4, DP-5, DP-6, DP-7. The correlation of the degradation product in Dofetilide and its stress conditions were shown in Figures 11-16 (mass spectrum) and fragmentation pattern shown in Figures 17-20.

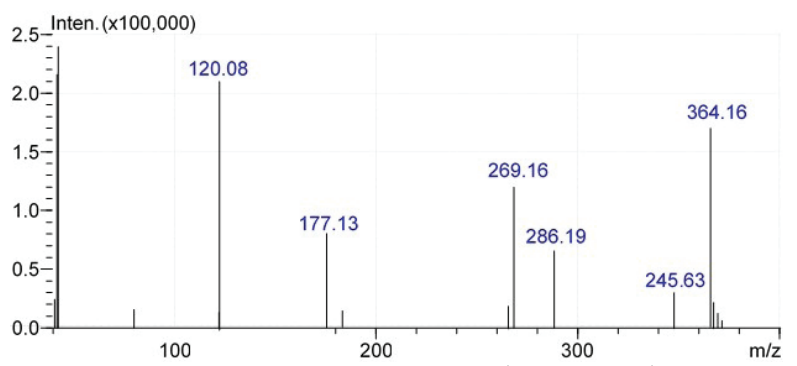

Figure 11. MS/MS spectrum of the DP-1 ( $\mathrm{m} / \mathrm{z} 364.17)$.

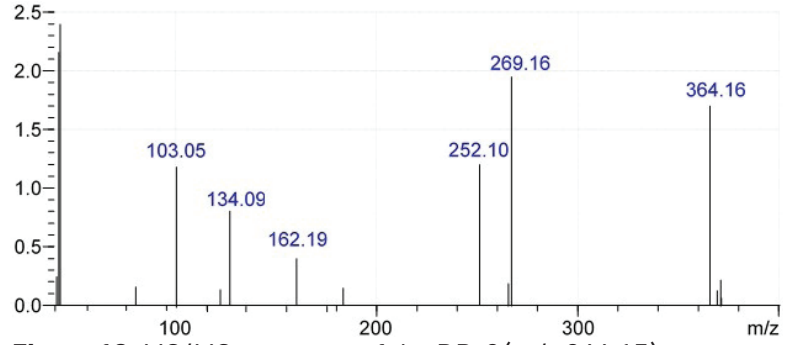

Figure 12. MS/MS spectrum of the DP-2 (m/z 364.17).

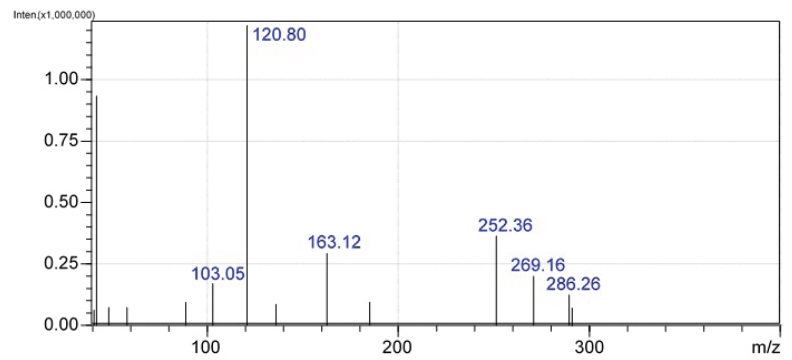

Figure 13. MS/MS spectrum of the DP-3 and DP-4 (m/z 285.18).

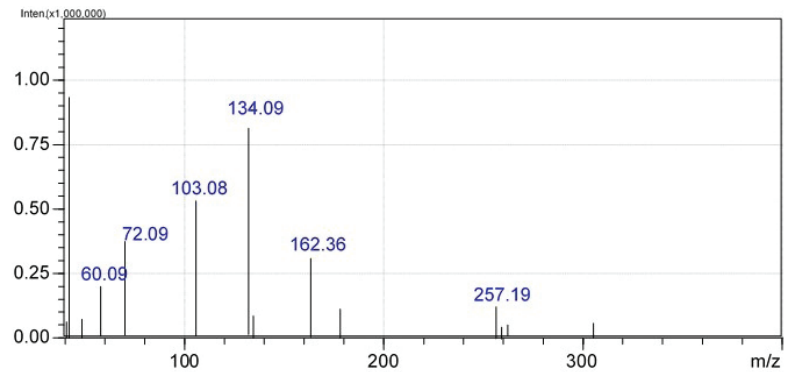

Figure 14. MS/MS spectrum of DP-5 (m/z 257.13).

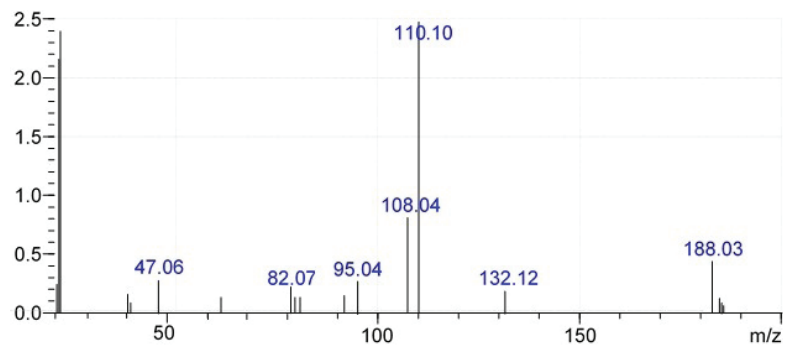

Figure 15. MS/MS spectrum of DP-6 (m/z 188.04).

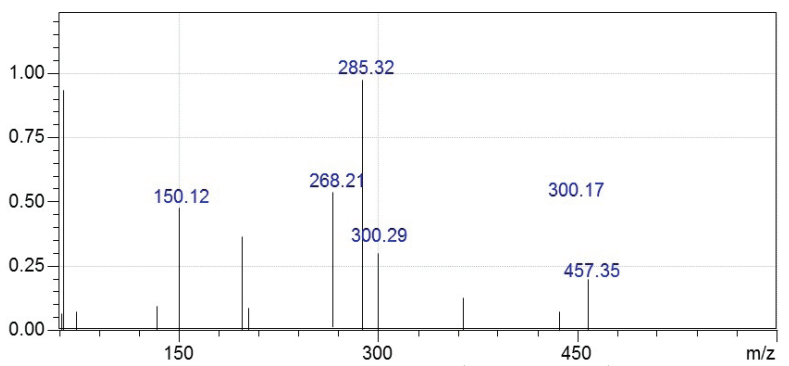

Figure 16. MS/MS spectrum of DP-7 (m/z 363.14). 
Fragmentation Pattem of the Dofetilide

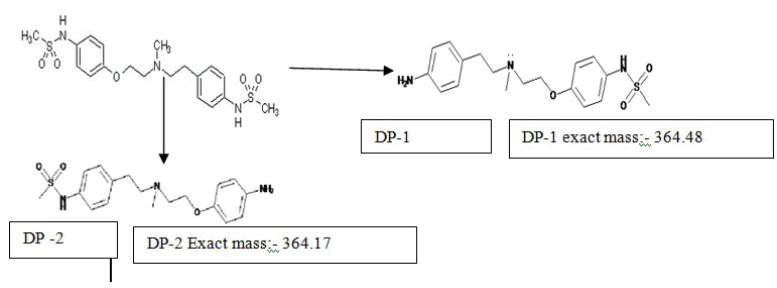

Figure 17. Possible degradation pathway in neutral condition.

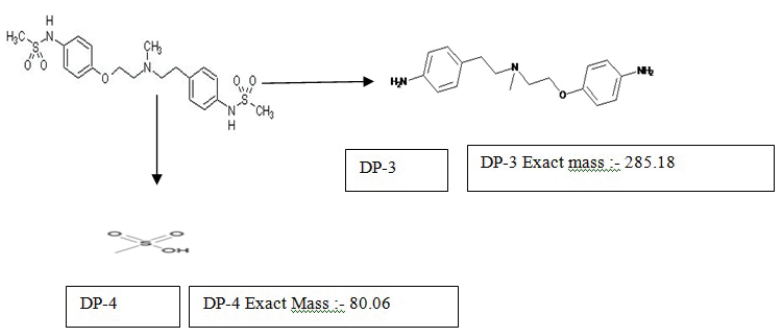

Figure 18. Possible degradation pathway in alkali stress condition.

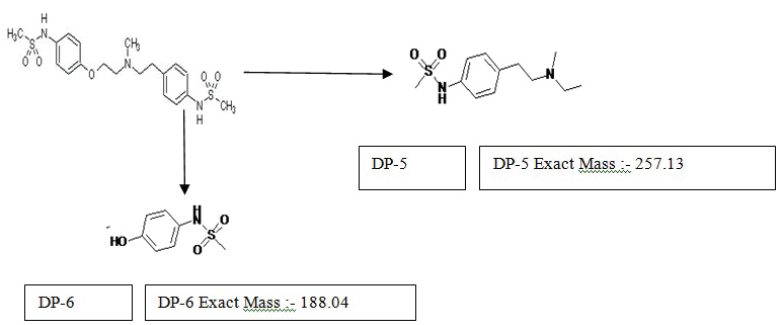

Figure 19. Possible degradation pathway in acid stress condition.

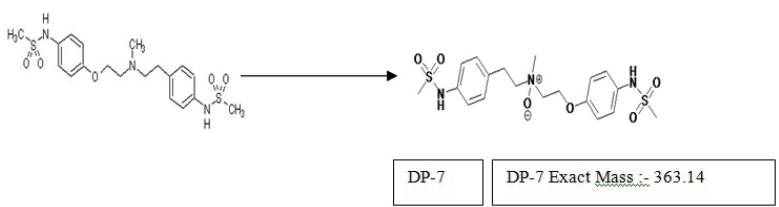

Figure 20. Possible Degradation pathway in oxidative stress condition.

\section{CONCLUSION}

The HPTLC method developed for its linearity, range, precision studies, LOD and LOQ can be used for the routine quality control of the drug dofetilide in bulk drugs. The degradation of the drug under various stress conditions indicates the storage conditions for the drug and drug product during its shelf life. Moreover, the degradation pathway of a drug can help in the future to identify the impurities and for the impurity profiling of dofetilide.

Peer-review: Externally peer-reviewed.

Author Contributions: Conception/Design of Study- R.B., C.G.B.; Data Acquisition- K.C., Y.Z., R.B.; Data Analysis/Interpretation- R.B., C.G.B.;
Drafting Manuscript- R.B., Y.Z..; Critical Revision of Manuscript- C.G.B., K.C.; Final Approval and Accountability- R.B., Y.Z., K.C., C.G.B.; Technical or Material Support- R.B., C.G.B.; Supervision- K.C., Y.Z.

Conflict of Interest: The authors have no conflict of interest to declare.

Financial Disclosure: Authors declared no financial support.

Acknowledgement: We thank Dr. S. S. Chitlange, Principal, Dr. D. Y. Patil IPSR for providing necessary facility.

\section{REFERENCES}

- $\quad$ Al-Dashti, R., \& Sami, M. (2001). Dofetilide: A new class III antiarrhythmic agent. The Canadian Journal of Cardiology, 17(1), 63-67.

- $\quad$ Aktas, M. K., Shah, A. H., \& Akiyama, T. (2007). Dofetilide-induced long QT and torsades de pointes. Annals of Noninvasive Electrocardiology, 12, 197-202.

Bhole, R. P., Biradar, P., \& Bonde, C. G. (2018). Development and validation of stability indicating HPTLC method for estimation of dasatinib and characterization of degradation products by using mass spectroscopy. Eurasian Journal of Analytical Chemistry, 13(4), 1-11.

- $\quad$ Bhole, R. P., Naksarkhre, S., \& Bonde, C. G. (2019). A stability indicating HPTLC method for apremilast and identification of degradation products using MS/MS. Journal of Pharmaceutical Sciences and Research, 11(5), 1861-1869.

- Bhole, R. P., Zombade, T., Bonde, C. G., \& Zambare, Y. B. (2019). Identification and characterization of degradation products by using Ms-Ms studies for developed and validated stability indicating HPTLC method for estimation of Nintedanib Esylate in pharmaceutical dosage form. Eurasian Journal of Analytical Chemistry, 14(2), 60-70.

- Bhole, R. P., Shinde, S. S., Chitlange, S. S., \& Wankhede, S. B. (2015). A high-performance thin layer chromatography (HPTLC) method for simultaneous determination of diphenhydramine hydrochloride and naproxen sodium in tablets. Analytical Chemistry Insights, 10, 47-51.

- Bonthagarala, B., Ch, P. K. (2003). Formulation and evalution of lansoprazole delayed release. Journal of Pharma Research, 6, 108-114.

- Bhole, R. P., \& Tamboli, F. (2018). Development and validation of stability indicating HPTLC-MS method for estimation of empagliflozin in pharmaceutical dosage form. Analytical Chemistry Letters, 8(2), 244-256.

- Clusin, W. T. (2003). Calcium and cardiac arrhythmias: DADs, EADs, and alternans. Critical Reviews in Clinical Laboratory Sciences, 40, 337-375.

- Chi, Z., Liu, R., \& Wang, K. (2017). A sensitive and rapid LC-MS-MS method for simultaneous determination of propafenone and its active metabolite 5-Hydroxypropafenone in human plasma and its application in a pharmacokinetic study. Journal of Chromatographic Science, 55(9), 911-917.

- $\quad$ Ceresole, R., Moyano, M. A., Pizzorno, M. T., \& Segall, A. (2007). Validated reversed phase HPLC method for the determination of atenolol in the presence of its major degradation product. Journal of Liquid Chromatography \& Related Technologies, 29(20), 3009-3019.

- $\quad$ Fegade, J. D., Bhole, R. P., Patil, V. R., \& Chaudhari, R.Y. (2009). Development and validation of reverse phase high performance liquid chromatographic method for simultaneous estimation of paracetamol and piroxicam in tablet. International Journal of PharmTech Research, 1(2),184-190.

(2005) ICH HARMONISED TRIPARTITE GUIDELINE, https://www. ich.org/fileadmin/Public. Accessed on 04/05/2019. 
- Jadhav, S. A., Nimbalkara, K. P., Mathad, V. T., \& Mali, A. C. (2013). Stability indicating RP-HPLC method for the determination of dronedarone hydrochloride and its potential process-related impurities in bulk drug and pharmaceutical dosage form. American Journal of Analytical Chemistry, 4(6), 323-335.

- $\quad$ Krafte, D. S., \& Volberg, W. A. (1994). Voltage dependence of cardiac delayed rectifier block by methanesulfonamide class III antiarrhythmic agents. Journal of Cardiovascular Pharmacology, 23, 37-41.

- Kaddar, N., Pilote, S., Wong, S., Caillier, B., \& Patoine, D. (2013). Simultaneous determination of dofetilide and amlodipine in plasma by HPLC. Journal of Chromatography and Separation Techniques, 4(6), 192.

- Mounsey, J. P., \& DiMarco, J. P. (2007). Cardiovascular drugs. Dofetilide. Circulation, 102, 2665-2670.

- Qile, M., Henriett, D. M., \& David, S. (2019). LUF7244, an allosteric modulator/activator of Kv11.1 channels, counteracts dofetilide induced torsades de pointes arrhythmia in the chronic atrioventricular block dog model. British Journal of Pharmacology, 176, 3871-3885.

- $\quad$ Rakibe, U., Tiwari, R., Mahajan, A., Rane, V., \& Wakte, P. (2018). LC and LC-MS/MS studies for the identification and characterization of degradation products of acebutolol. Journal of Pharmaceutical Analysis, 8(6), 357-365.
Shivashankar, V., \& Gandhimathi, M. (2005). RP-HPLC method development and validation for the analyisis of dronedarone hydrochloride in tablet dosage form. Journal of Pharmacreations, 2(4), 66-71.

- Udin, E. F., Sung, S., Hunge, K. M., \& Hu, S. (2019). Development and validation of a UPLC-MS/MS analytical method for dofetilide in mouse plasma and urine, and its application to pharmacokinetic study. Journal Of Pharmaceutical And Biomedical Analysis, 172, 183-188.

- Woolf, V. A., Miler, D. G., \& Gosting, L. J. (1962). Isothermal diffusion measurements on the system $\mathrm{H} 2 \mathrm{O}$-Glycine-KCl at 25; Tests of the onsager reciprocal relation. Journal of American Chemical Society, 84(3), 317-331.

- Wells, R., Khairy, P., Harris, L., Anderson, C. C., \& Balaji, S. (2009). Dofetilide for atrial arrhythmias in congenital heart disease: A multicenter study. Pacing and clinical electrophysiology, 32, 13131318. 